02

\title{
Спектры пропускания и оптические свойства мезопористого фотонного кристалла на основе анодного оксида алюминия
}

\author{
(C) B.C. Горелик ${ }^{1,2}$, M.M. Яшин ${ }^{2}$, Dongxue $B i^{2}$, Guang Tao Fei ${ }^{3}$ \\ ${ }^{1}$ Физический институт им. П.Н. Лебедева РАН, \\ 119991 Москва, Россия \\ ${ }^{2}$ Московский государственный технический университет им. Н.Э. Баумана, \\ 105005 Москва, Россия \\ ${ }^{3}$ Key Laboratory of Materials Physics and Anhui Key Laboratory of Nanomaterials and Nanotechnology, \\ Institute of Solid State Physics, Hefei Institutes of Physical Science, Chinese Academy of Sciences, \\ Hefei, 230031 China \\ e-mail: gorelik@sci.lebedev.ru
}

Поступила в редакцию 07.08.2017 г.

Исследованы оптические свойства одномерной фотонно-кристаллической пленки, образованной методом электрохимического протравливания алюминиевой фольги с периодом кристаллической решетки $\approx 380$ нм. Проведено сопоставление экспериментальных данных по спектрам пропускания и отражения в области первой, второй и третьей стоп-зон анодного фотонного кристалла оксида алюминия с теоретической зависимостью, полученной из известного дисперсионного соотношения. Проанализирована возможность создания селективных узкополосных светофильтров на основе мезопористых одномерных фотонных кристаллов. Установлены условия для усиления электромагнитного поля лазерного излучения с длиной волны $532 \mathrm{Hм}$ при нормальном падении электромагнитного излучения на поверхность фотонного кристалла. Проанализирована возможность генерации оптических гармоник в условиях резкого возрастания эффективного поля возбуждающего излучения в мезопористом фотонном кристалле анодного оксида алюминия, заполненном иодатом лития.

DOI: $10.21883 /$ OS.2018.02.45519.177-17

\section{Введение}

В настоящее время известны различные типы светофильтров [1-6]: абсорбционные, поляризационные, интерференционные, ногч-фильтры и др. При этом весьма актуальной остается проблема создания узкополосных светофильтров с управляемыми оптическими характеристиками. С этой точки зрения большой интерес представляют исследования фотонных кристаллов [7-10], перспективных для создания на их основе узкополосных светофильтров с управляемыми полосами пропускания и отражения. Фотонные кристаллы представляет собой среды, в которых диэлектрическая проницаемость периодически изменяется в пространстве. Одним из примеров фотонных кристаллов являются одномерные фотонные кристаллы [11-13], построенные из двух различных чередующихся слоев с показателями преломления $n_{1}$ и $n_{2}$. В спектре отражения такого кристалла присутствуют так называемые стоп-зоны (запрещенные зоны). Стоп-зоны представляют собой спектральные области, в которых наблюдается сильное отражение электромагнитного излучения от поверхности кристалла. Спектральные положения стоп-зон зависят от параметров фотонного кристалла: периода фотонно-кристаллической решетки и значений показателей преломления слоев $n_{1}$ и $n_{2}$.

Ранее исследовались оптические свойства глобулярных фотонных кристаллов, образованных из плотноупа- кованных шариков плавленого кварца - $\mathrm{SiO}_{2}$ (кремнезема) - в виде гранецентрированной кубической решетки [14-17]. В последние годы был развит метод получения одномерных фотонно-кристаллических пленок в результате электрохимического травления алюминиевой фольги $[18,19]$. В результате были получены мезопористые фотонно-кристаллические пленки анодного оксида алюминия, период которых зависит от режима травления и может изменяться в диапазоне $100-500 \mathrm{~nm}$. При этом изменение показателей преломления $n_{1}$ и $n_{2}$ в смежных слоях фотонного кристалла осуществляется за счет различной степени пористости этих слоев, регулируемой в процессе анодного травления алюминиевой фольги в кислотной среде. В настоящей работе была поставлена задача исследования оптических свойств мезопористого одномерного фотонного кристалла на основе оксида алюминия с целью управления их спектрами пропускания и отражения.

\section{Методика эксперимента и экспериментальные результаты}

В качестве образцов для исследования использовались тонкие фотонно-кристаллические пленки мезопористого анодного оксида алюминия. На рис. 1 приведены фотографии исследуемого образца с одномерной фотоннокристаллической пленкой, полученные при различных углах падения излучения лампы накаливания. 
$a$

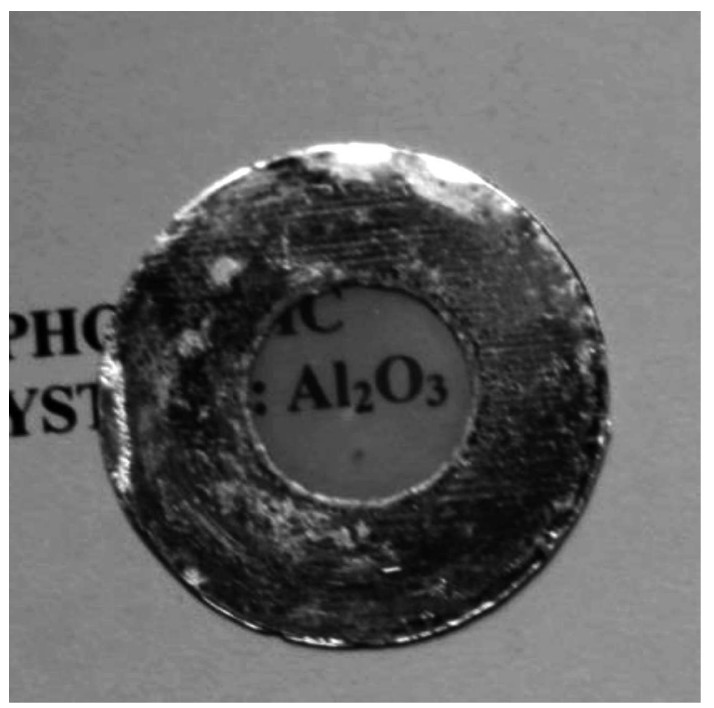

$b$

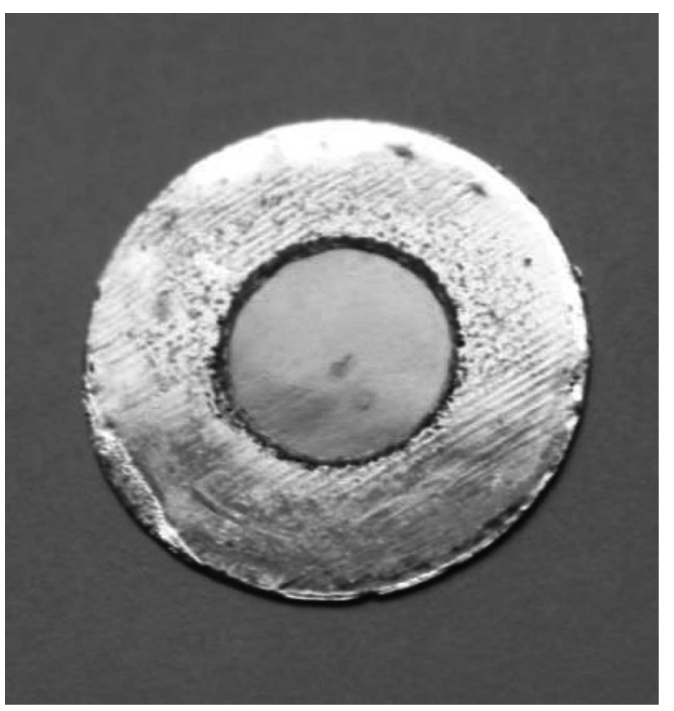

Рис. 1. Вид поверхности одномерного фотонного кристалла на основе оксида алюминия при различных углах наблюдения $(a, b)$ отраженного излучения.

$a$

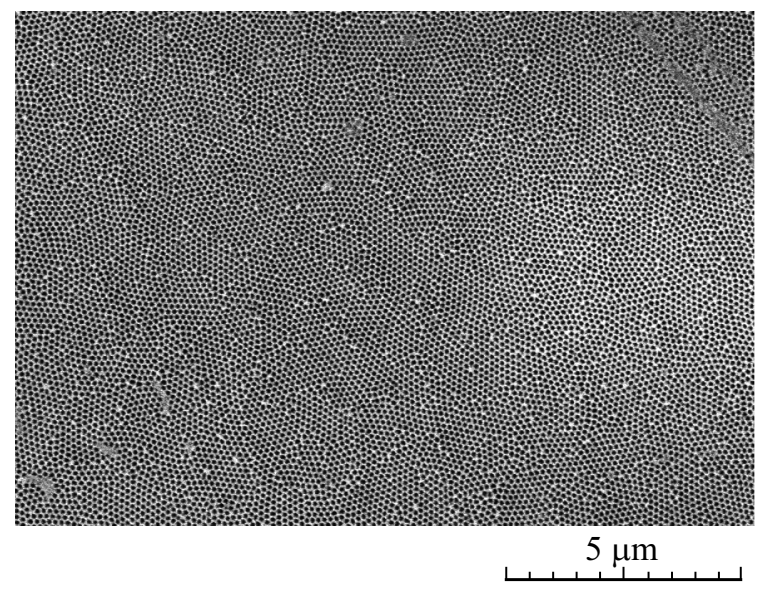

$b$

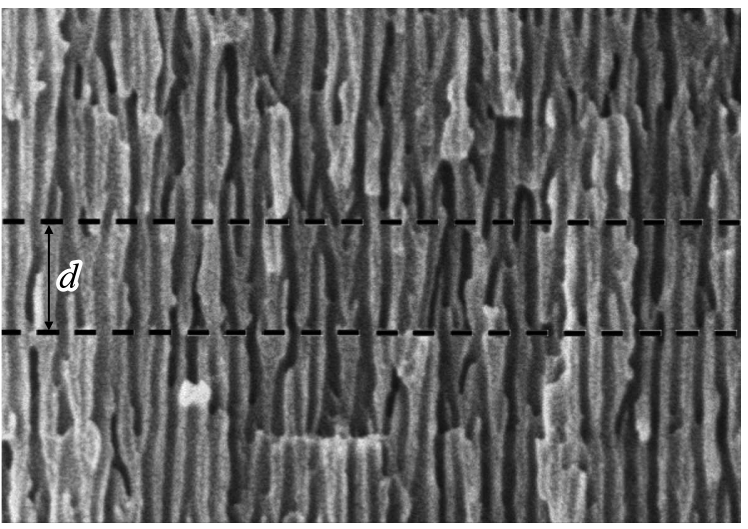

$1 \mu \mathrm{m}$

Рис. 2. Электронная фотография поверхности $(a)$ и в разрезе $(b)$ одномерного фотонного кристалла на основе мезопористого оксида алюминия; $d=380 \pm 10 \mathrm{~nm}$.

В центре образца (рис. 1) присутствует фотоннокристаллическая пленка мезопористого оксида алюминия. Эта пленка окружена кольцевым слоем алюминиевой фольги. Толщина пленки составляла около $20 \mu \mathrm{m}$. Рис. 1 иллюстрирует изменение цвета фотонного кристалла в зависимости от угла наклона $\theta$ одномерного мезопористого фотонного кристалла на основе мезопористого оксида алюминия. Рис. 2 иллюстрирует изображения микроструктуры поверхности $(a)$ и бокового среза $(b)$ исследуемой мезопористой фотонно-кристаллической пленки, полученные с помощью электронного микроскопа.

Как видно из рис. 2, $a$, наблюдается присутствие пор с диаметром $D \approx 80 \mathrm{~nm}$ в объеме фотонно-кристаллической пленки, образованных в результате электрохи- мического травления алюминиевой фольги. Период $d$ фотонно-кристаллической пленки составляет $\approx 380 \mathrm{~nm}$ (рис. 2, $b$ ).

Были получены спектры пропускания электромагнитного излучения фотонно-кристаллической пленкой. Схема соответствующей экспериментальной установки представлена на рис. 3. Свет от широкополосного источника излучения 1 фокусировался с помощью линзы 2 на входную щель монохроматора 3. На выходе из монохроматора излучение с фиксированной длиной волны в виде параллельного пучка направлялось на фотонно-кристаллическую пленку 4. Зарегистрированный детектором 5 спектр пропускания анализировался в цифровом виде компьютером 6. Таким образом были получены спектры пропускания (рис. 4, $a$ ) фотонно-кристаллической 


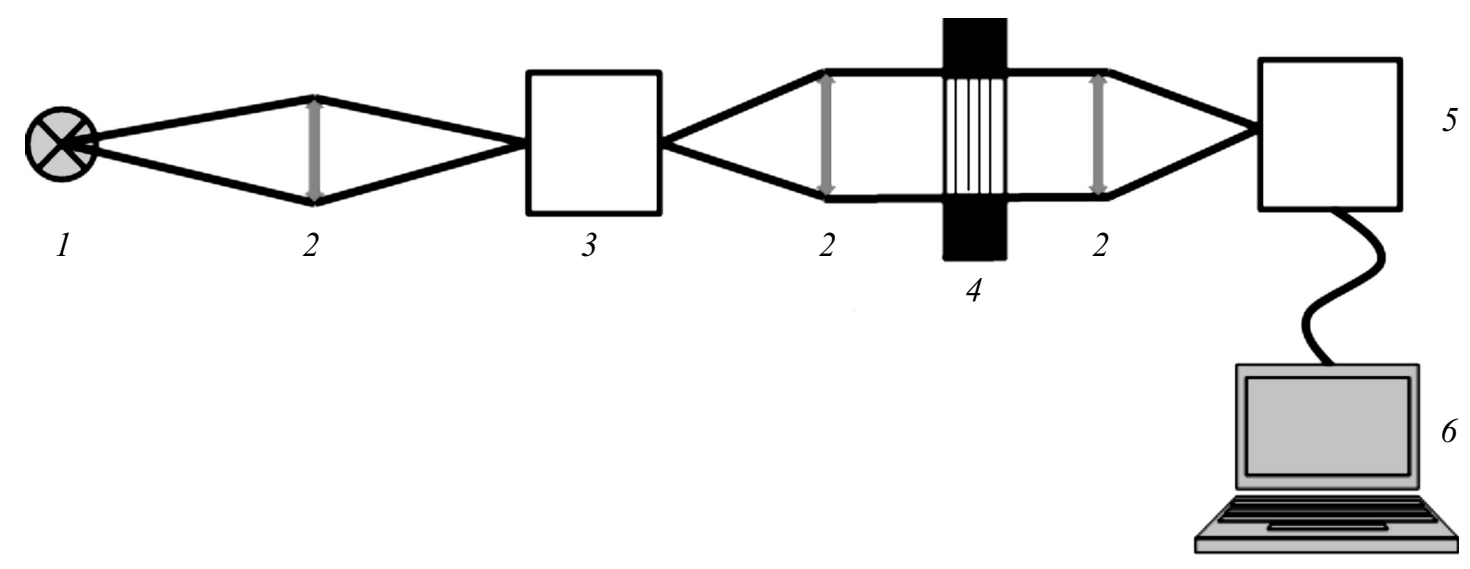

Рис. 3. Схема установки для регистрации спектров пропускания излучения через фотонно-кристаллическую пленку оксида алюминия: 1 - источник излучения, 2 - линза, 3 - монохроматор, 4 - фотонный кристалл, 5 - детектор, 6 - компьютер.
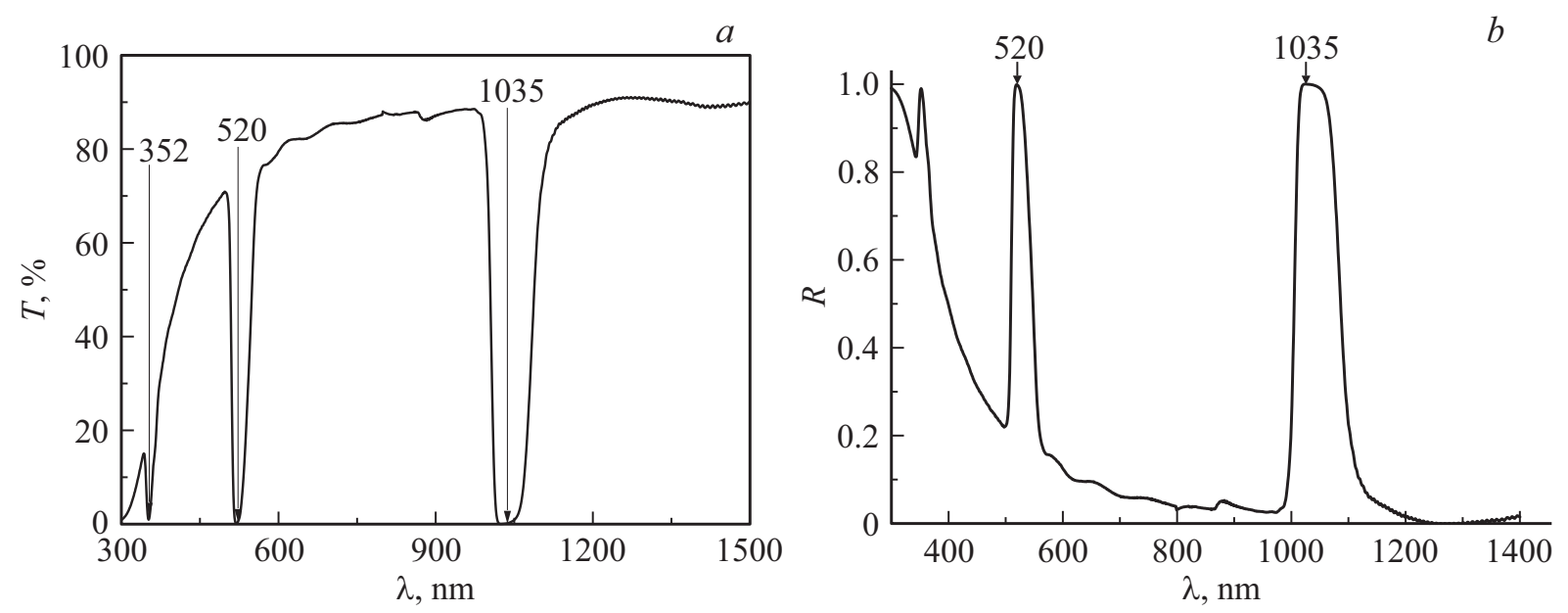

Рис. 4. Спектры пропускания $(a)$ и отражения $(b)$ широкополосного излучения от поверхности фотонно-кристаллической пленки.

пленки с использованием широкополосного излучения ксеноновой лампы. На рис. 4, $а$ приведен полученный спектр пропускания $T(\lambda)$ исследуемой фотонно-кристаллической пленки в диапазоне длин волн $300-1500 \mathrm{~nm}$. На рис. 4, $b$ приведен соответствующий спектр отражения, полученный с использованием известного соотношения $R(\lambda)=1-T(\lambda)$.

Как видно из рис. 4, $a$, обнаруживаются резкие минимумы в спектрах пропускания электромагнитного излучения ксеноновой лампы от кристаллической пленки одномерного фотонного кристалла в области первой, второй и третьей стоп-зон, они соответствуют длинам волн 1035, 520 и $352 \mathrm{~nm}$. Соответственно в спектрах отражения обнаруживаются (рис. 4,b) полосы отражения, обусловленные присутствием стоп-зон в спектре исследуемого фотонного кристалла.

\section{Обсуждение результатов эксперимента}

При нулевом угле падения электромагнитного излучения на поверхность фотонно-кристаллической пленки спектральные положения стоп-зон фотонного кристалла определятся из известного соотношения Бульфа-Брэгга:

$$
m \lambda_{m}=2 d n_{\mathrm{ef}}\left(\lambda_{m}\right)
$$

Здесь $m=1,2,3, \ldots$ - номера соответствующих стопзон; $\lambda_{m}$ - длина волны, соответствующая спектральному положению соответствующей стоп-зоны; $d=a_{1}+a_{2}-$ период кристаллической решетки; $a_{1}=a_{2}$ - толщины слоев; $n_{1}, n_{2}-$ показатели преломления слоев; $n_{\mathrm{ef}}$ - эффективный показатель преломления:

$$
n_{\mathrm{ef}}^{2}=\frac{a_{1}}{a_{1}+a_{2}} n_{1}^{2}+\frac{a_{2}}{a_{1}+a_{2}} n_{2}^{2} .
$$

Показатель преломления первого слоя фотонно-кристаллической пленки $n_{1}\left(\lambda_{m}\right)$ в области 2-й стоп-зоны рассчитывался из выражения [20]

$$
n_{1}\left(\lambda_{m}\right)=\sqrt{(1-\delta) n_{\mathrm{Al}_{2} \mathrm{O}_{3}}^{2}\left(\lambda_{m}\right)+\delta n_{\text {air }}^{2}}
$$

Здесь $\delta$ пористость слоя, $n_{\mathrm{Al}_{2} \mathrm{O}_{3}}\left(\lambda_{m}\right)$ и $n_{\text {air }}-$ показатели преломления монокристалла оксида алюминия и 
воздуха. Ширина $\Delta \lambda_{m}$ и спектральное положение $\lambda_{m}$ стоп-зоны с порядковым номером $m=1$ связаны с показателями преломления слоев известным соотношением [20]

$$
\frac{\Delta \lambda_{m}}{\lambda_{m}}=\frac{4}{\pi} \frac{n_{1}\left(\lambda_{m}\right)-n_{2}\left(\lambda_{m}\right)}{n_{1}\left(\lambda_{m}\right)+n_{2}\left(\lambda_{m}\right)} .
$$

Из соотношения (4) получаем формулу для расчета показателя преломления второго слоя:

$$
n_{2}\left(\lambda_{m}\right)=n_{1}\left(\lambda_{m}\right) \frac{4 \lambda_{m}-\pi \Delta \lambda_{m}}{4 \lambda_{m}+\pi \Delta \lambda_{m}}
$$

На основе приведенных формул (2)-(4) при подстановке значений положения максимума второй стопзоны $\lambda_{m}$ и еe спектральной ширины $\Delta \lambda_{m}$, определенных по экспериментальному спектру пропускания, представленного на рис. 4, $a$, рассчитаны период $d \approx 380 \mathrm{~nm}$, значения эффективного показателя преломления $\left(n_{\mathrm{ef}}=1.37\right)$ и показателей преломления периодических слоев $\left(n_{1}=1.44\right.$ и $\left.n_{2}=1.30\right)$ исследуемой фотонно-кристаллической пленки.

Для анализа наблюдаемых оптических свойств одномерного фотонного кристалла воспользуемся моделью Кронига-Пенни. При этом закон дисперсии электромагнитных волн в одномерном фотонном кристалле с бесконечным числом слоев определяется выражением $[21,22]$

$$
\begin{aligned}
\cos k d= & \cos k_{1} a_{1} \cos k_{2} a_{2} \\
& -\frac{1}{2}\left(\frac{n_{1}}{n_{2}}+\frac{n_{2}}{n_{1}}\right) \sin k_{1} a_{1} \sin k_{2} a_{2} .
\end{aligned}
$$

Здесь $n_{1}$ и $n_{2}$ - показатели преломления слоев композита, толщины которых равны $a_{1}$ и $a_{2}, k_{1}=\frac{\omega}{c} n_{1}$; $k_{2}=\frac{\omega}{c} n_{2} ; c=3 \cdot 10^{8} \mathrm{~m} / \mathrm{c}-$ скорость света в вакууме; $d=a_{1}+a_{2}-$ период кристаллической структуры. На рис. 5 приведены рассчитанные с использованием соотношений (5) дисперсионные кривые зависимости $\omega(k)$.

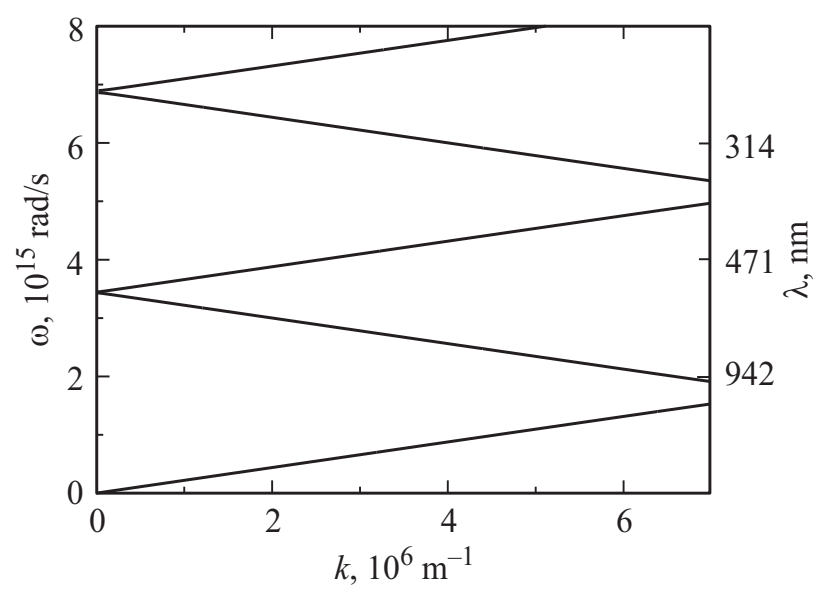

Рис. 5. Дисперсионные кривые зависимости $\omega(k)$ электромагнитных волн в фотонном кристалле.

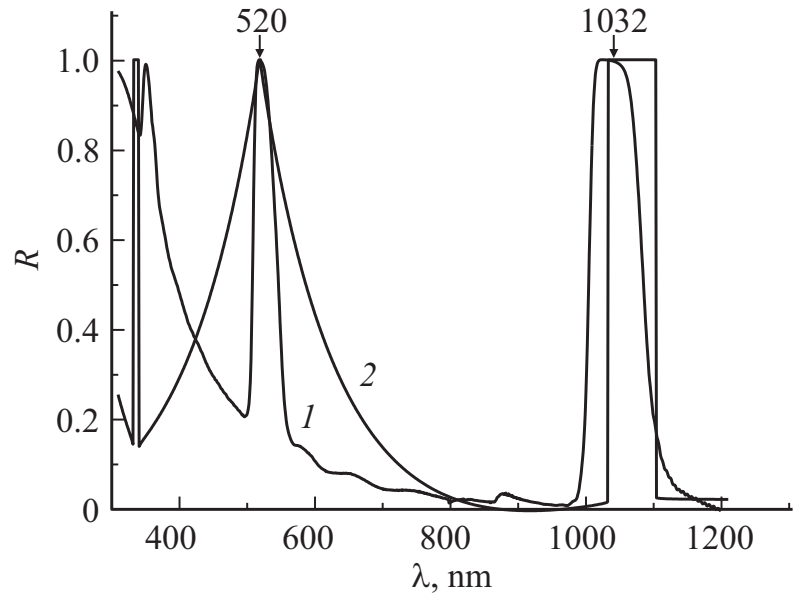

Рис. 6. Сопоставление теоретических (кривая 2) и экспериментальных (кривая 1) данных спектров отражения широкополосного излучения от поверхности исследуемой фотоннокристаллической пленки на основе пористого оксида алюминия.

Используя экспериментально полученные данные о спектрах отражения при нормальном падении исследуемого фотонного кристалла, была построена теоретическая зависимость коэффициента отражения от длины волны $R(\lambda)$ излучения. На рис. 6 проводится сопоставление теоретических (кривая 2) и экспериментальных (кривая 1) данных спектров отражения исследованных образцов.

Как видно из этого рисунка, экспериментально зарегистрированные спектры отражения (кривые 1 на рис. 6) близки к расчетным зависимостям (кривые 2). Наблюдаемые отличия кривых 1 и 2 обусловлены необходимостью учета конечного числа слоев в анализируемых фотонно-кристаллических пленках.

В теории расчет проводился для фотонного кристалла с бесконечным числом слоев с использованием формулы Френеля

$$
R(\omega)=\left|\frac{\frac{c K(\omega)}{\omega}-1}{\frac{c K(\omega)}{\omega}+1}\right|^{2} .
$$

Далее нами был проведен анализ характеристик узкополосного светофильтра, создаваемого на основе обсуждаемого фотонного кристалла и обеспечивающего селективное отражение лазерного излучения с длиной волны $\lambda=532 \mathrm{~nm}$. В связи с этим была исследована вторая стоп-зона $(m=2)$. Изменение характеристик мезопористого одномерного фотонного кристалла может быть достигнуто при внедрении в поры такого кристалла других веществ. При этом изменяется эффективный показатель преломления, что приводит в соответствии с соотношением Брэгга (1) к изменению спектрального положения стоп-зон и их спектральной ширины. В качестве внедряемого вещества в поры одномерного мезопористого фотонного кристалла на основе оксида алюминия был выбран иодата лития $\left(\mathrm{LiIO}_{3}\right.$, в дальнейшем LIO). 
Таблица 1. Зависимость максимума отражения на длине волны $\lambda_{m}$ от концентрации $\eta$ иодата лития в порах фотонного кристалла $n_{\mathrm{ef}}$

\begin{tabular}{c|c|c|c|c|c}
\hline$\eta, \%$ & $n_{\mathrm{LIO}}$ & $n_{1}$ & $n_{2}$ & $n_{e f}$ & $\lambda_{m}, \pm 0.1 \mathrm{~nm}$ \\
\hline 0 & 1.000 & 1.440 & 1.300 & 1.372 & 520.0 \\
1 & 1.013 & 1.443 & 1.304 & 1.375 & 522.0 \\
2 & 1.025 & 1.447 & 1.308 & 1.379 & 523.4 \\
3 & 1.038 & 1.451 & 1.312 & 1.383 & 525.0 \\
4 & 1.050 & 1.455 & 1.317 & 1.388 & 526.6 \\
5 & 1.063 & 1.459 & 1.321 & 1.392 & 528.3 \\
6 & 1.075 & 1.464 & 1.326 & 1.397 & 530.1 \\
7 & 1.087 & 1.468 & 1.331 & 1.402 & 531.9 \\
8 & 1.099 & 1.473 & 1.336 & 1.406 & 533.7 \\
9 & 1.111 & 1.478 & 1.342 & 1.412 & 535.7 \\
10 & 1.123 & 1.483 & 1.347 & 1.417 & 537.7
\end{tabular}

Показатель преломления иодата лития $n_{\mathrm{LIO}}=1.89817$. Внедрение данного вещества в поры предполагается путем его растворения в воде с последующим выпариваем жидкости. В зависимости от концентрации иодата лития в пористом оксиде алюминия изменяется эффективный показатель преломления $n_{\mathrm{ef}}$ всего фотонного кристалла. Это способствует изменению положения и ширины стоп-зон данного фотонного кристалла. Была рассчитана зависимость концентрации $\eta$ внедренного LIO в поры фотонного кристалла от смещения второй стопзоны исследуемого образца на заданную длину волны $\lambda_{m}=532 \mathrm{~nm}$. Данная зависимость представлена в табл. 1 .

Как видно из этой таблицы, при заполнении пор мезопористого фотонного кристалла на основе оксида алюминия (образец № 1) на 17\% иодатом лития первая стоп-зона кристалла смещается на длину волны $\approx 531 \mathrm{~nm}$. Точная подстройка положения стопзоны будет обеспечиваться путем нагревания фотоннокристаллической пленки до заданной температуры. При этом изменяется эффективный показатель преломления фотонного кристалла, что, согласно формуле (3), приводит к изменению положения стоп-зоны. Теоретически такая температурная зависимость описывается следующим соотношением:

$$
n=n_{0}+\frac{d n}{d T} \Delta T
$$

При этом $n-$ полученный показатель преломления при нагревании кристалла на температуру $\Delta T, n_{0}-$ исходный показатель преломления, $\frac{d n}{d T}-$ табличные данные. Исходя из этого была получена зависимость спектрального положения второй стоп-зоны фотонного кристалла от температуры. Данная зависимость представлена в табл. 2. При этом предполагается, что угол падения света на поверхность одномерного мезопористого фотонного кристалла близок к нулю.

Как видно из табл. 1 и 2, при заполнении пор мезопористой фотонно-кристаллической пленки оксида алюминия на 7\% иодатом лития вторая стоп-зона фотонного кристалла смещается на длину волны $\lambda_{m} \approx 531.9 \mathrm{~nm}$. При этом точная подстройка положения стоп-зоны на длину волны $\lambda_{m} \approx 532 \mathrm{~nm}$ достигается путем нагревания фотонно-кристаллической пленки до температуры $29^{\circ} \mathrm{C}$ (табл. 2). Так как нам известны макропараметры фотонного кристалла (диаметр $D=1 \mathrm{~cm}$, толщина $h=20 \mu \mathrm{m}$ ), то мы можем вычислить необходимую вводимую массу $m_{\mathrm{LIO}}$ иодата лития в поры фотонно-кристаллической пленки для каждого случая. Фотонный кристалл представляет собой цилиндр с объемом $V=\pi R^{2} h$, следовательно, $V=2 \cdot 10^{-9} \mathrm{~m}^{3}$ или $0.002 \mathrm{~cm}^{3}$. Так как поры кристалла занимают половину всего его объема, то объем пор составляет $V_{\text {пор }}=V / 2=1 \cdot 10^{-9} \mathrm{~m}^{3}=1 \cdot 10^{-3} \mathrm{~cm}^{3}$. Следовательно, масса фотонного кристалла равна $m=395 \cdot 10^{-5} \mathrm{~g}$ или $3.95 \mathrm{mg}$. Таким образом, масса вводимого в поры фотонно-кристаллической пленки иодата лития равна $m_{\mathrm{LIO}}=V_{\mathrm{LIO}} \rho$, где $V_{\mathrm{LIO}}$ - объем иодата лития, занимаемый в порах фотонно-кристаллической пленки, $\rho=4.08 \mathrm{~g} / \mathrm{cm}^{3}$ - плотность иодата лития. Таким образом, установлены необходимые параметры $\left(\lambda_{m}=532 \mathrm{~nm}\right.$ - спектральное положение стоп-зоны, $\eta$, $7 \%$ - концентрация иодата лития в порах кристалла, $m_{\mathrm{LIO}}, 0.3 \mathrm{mg}$ - масса вводимого иодата лития и $\Delta \lambda$, $21 \mathrm{~nm}$ - спектральная ширина стоп-зоны) фотонного кристалла для создания на его основе узкополосного регулируемого светофильтра.

На рис. 7 представлена схема установки с применением обсуждаемой мезопористой фотонно-кристаллической пленки для разделения линий генерации многолучевых лазеров. Предполагается использование лазерного излучения 1 с несколькими оптическими гармониками на длинах волн 266, 532 и $1064 \mathrm{~nm}$. При этом используются как пропускающие, так и отражательные свойства фотонного кристалла 2 для выделения нужной длины волны лазерного источника излучения. При этом полного отражения избранной линии генерации можно добиться при изменении периода кристалличе-

Таблица 2. Зависимость положения максимума отражения на длине волны $\lambda_{m}$ от температуры $T$

\begin{tabular}{c|c|c|c|c|c|c|c}
\hline$T,{ }^{\circ} \mathrm{C}$ & $n_{\text {LIO }}$ & $n_{1}\left(\mathrm{Al}_{2} \mathrm{O}_{3}\right)$ & $n_{2}\left(\mathrm{Al}_{2} \mathrm{O}_{3}\right)$ & $n_{1}$ & $n_{2}$ & $n_{\mathrm{ef}}$ & $\lambda_{m}, \pm 0.01 \mathrm{~nm}$ \\
\hline 26 & 1.0874 & 1.4400 & 1.3000 & 1.2759 & 1.1984 & 1.2378 & 531.9 \\
27 & 1.0874 & 1.4400 & 1.3000 & 1.2760 & 1.1985 & 1.2378 & 531.9 \\
28 & 1.0875 & 1.4400 & 1.3000 & 1.2760 & 1.1985 & 1.2380 & 531.9 \\
29 & 1.0877 & 1.4400 & 1.3000 & 1.2761 & 1.1986 & 1.2379 & 532.0 \\
30 & 1.0877 & 1.4400 & 1.3000 & 1.2761 & 1.1986 & 1.2380 & 532.0
\end{tabular}




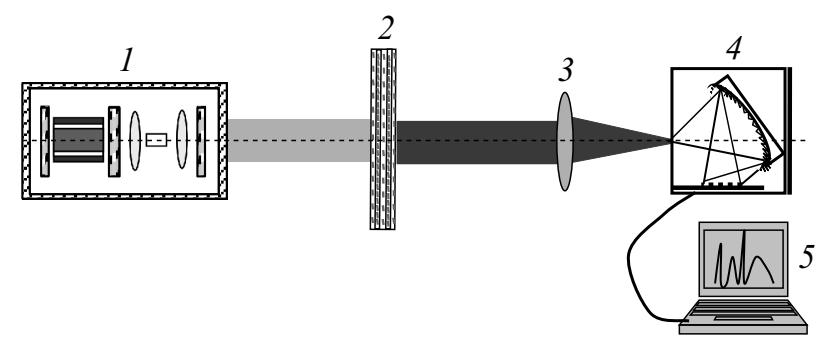

Рис. 7. Схема установки для разделения линий генерации: 1 - многолучевой лазер, 2 - фотонно-кристаллическая пленка, 3 - собирающая линза, 4 - миниспектрометр, 5 - компьютер.

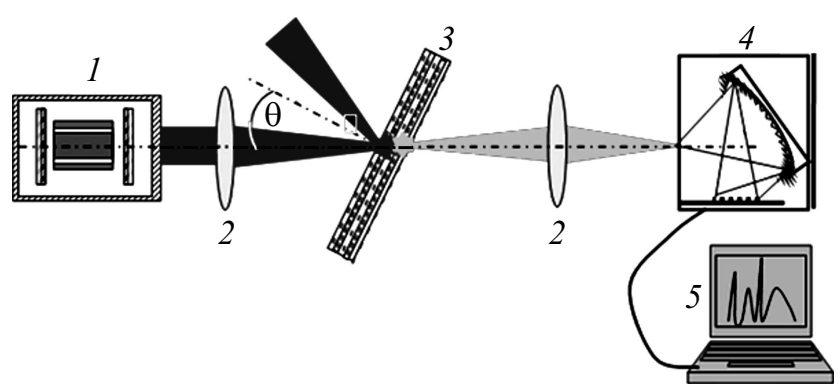

Рис. 8. Увеличение длины волны при помощи фотоннокристаллических пленок: 1 - лазер, 2 - конвергирующие линзы, 3 - фотонно-кристаллические пленки, 4 - спектрометр, 5 - ПК.

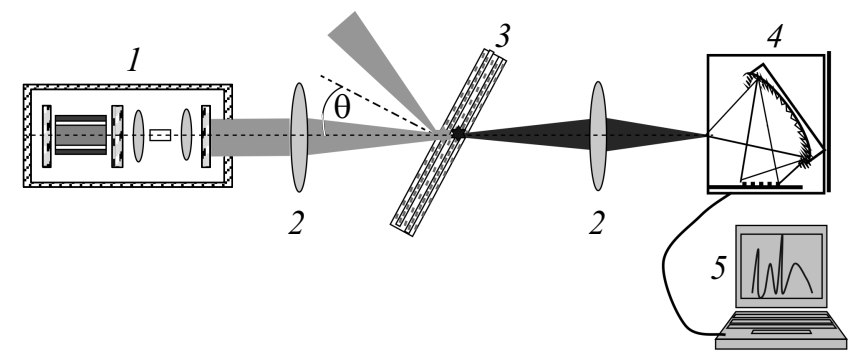

Pис. 9. Удвоение частоты на фотонно-кристаллической пленке: 1 - лазер, 2 - конвергирующие линзы, 3 - фотоннокристаллические пленки, $4-$ спектрометр, 5 - ПК.

ской решетки в процессе анодирования путем поворота фотонно-кристаллической пленки на определенный угол, а также при введении в поры фотонного кристалла диэлектрической среды, обеспечивающей необходимое изменение спектрального положения и ширины стопзоны. Таким образом генерируется лазерное излучение на интересующей нас заданной длине волны.

С помощью одномерного фотонного кристалла на основе мезопористого анодного оксида алюминия, поры которого заполнены нелинейно-оптической средой, возможно осуществлять генерацию оптических гармоник или субгармоник. В качестве нелинейно-оптических сред использовались водорастворимые соли $\mathrm{LiJO}_{3}, \mathrm{KJO}_{3}$, $\mathrm{NaNO}_{2}$. Заполнение пор осуществлялось в результате многократного выпаривания насыщенных водных растворов обсуждаемых солей при небольшом нагревании фотонно-кристаллической пленки. При генерации оптических гармоник или субгармоник частота лазерного излучения увеличивается или уменьшается в 2 раза соответственно.

Схема установки для удвоения частоты излучения $\left(\omega=2 \omega_{0}\right)$ мезопористой фотонно-кристаллической пленкой с порами, заполненными нелинейно-оптической средой, представлена на рис. 8. Рисунок 9 иллюстрирует соответствующую схему для генерации субгармоники $\left(\omega=\frac{\omega_{0}}{2}\right)$. При этом излучение от лазерного источника 1 падает под определенным углом $\theta$ на поверхность фотонного кристалла 3. Вторичное излучение с более низкой (для рис. 8) или более высокой (для рис. 9) длиной волны возбуждается внутри фотонно-кристаллической пленки и анализируется с помощью миниспектрометра 4 и компьютера 5.

\section{Заключение}

Таким образом, в настоящей работе исследован одномерный мезопористый фотонный кристалл анодного оксида алюминия с периодом кристаллической решетки $d=380 \mathrm{~nm}$. Установлены спектральные положения первых трех стоп-зон синтезированного фотонного кристалла. Проведено сопоставление экспериментальных и теоретических данных, полученных для спектров отражения. Наблюдается удовлетворительное согласие теории и эксперимента. Различия в спектрах отражения обусловлены необходимостью учета конечного числа слоев фотонно-кристаллической пленки и дисперсии эффективного показателя преломления. Изменение параметров фотонного кристалла, таких как период кристаллической решетки и количество вещества, введенного в поры фотонного кристалла, позволяют управлять спектральной шириной и положением стопзон. На основе исследованного анодного мезопористого фотонного кристалла могут быть созданы узкополосные регулируемые светофильтры, перспективные для использования при регистрации спектров комбинационного рассеяния, люминесценции и др. При этом для точной подстройки спектрального положения второй стоп-зоны исследуемого фотонного кристалла к длине волны возбуждающего излучения с длиной волн $532 \mathrm{~nm}$ в поры кристалла необходимо ввести иодат лития с известной массой $m_{\mathrm{LIO}}=0.3 \mathrm{mg}$. Показана возможность использования обсуждаемых одномерных мезопористых фотонных кристаллов в различных оптических устройствах [23-25], основанных на использовании оптических свойств фотонных кристаллов.

Работа выполнена при поддержке Российского фонда фундаментальных исследований [15-02-02882, 16-52-00026], фондом фундаментальных исследований республики Белоруссия [F16R-063], National Natural Science Foundation of China (№51471162, 51671183, 51502294) и China Scholarship Council. 


\section{Список литературы}

[1] Иофис E.A. Фотокинотехника. М.: Советская Энциклопедия, 1981. $447 \mathrm{c.}$

[2] Вестон К. Фильтры в фотографии. // Программные и оптические системы. М.: Арт-родник, 2010. 192 с.

[3] Carr P. N4PC. How to Build the „Synthetic“ Crystal Filter. 1990. ex. 215 P. 18.

[4] Ярославский Л.П., Мерзляков Н.С. Методы цифровой голографии. М.: Наука, 1977. 192 с.

[5] Подгорный И.М. Низкочастотный фильтр. // Радиолюбитель (2). 1996. 29 с.

[6] Попов С.И. // Радио-Дизайн (1). 1993. С. 6.

[7] Быков В.П. // ЖЭТФ. 1972. Т. 62. С. 505.

[8] Yablonovitch E. // Phys. Rev. Lett. 1987. V. 58. P. 2059.

[9] John S. // Phys. Rev. Lett. 1987. V. 58. P. 2486.

[10] Горелик В.С. // Квант. электрон. 2007. Т. 37. С. 409.

[11] Liu Yisen, Chang Yi, Ling Zhiyuan, Hu Xing, Li Yi. // Electrochem. Commun. 2011. V. 13. P. 1336.

[12] Svyakhovskiy S.E., Maydykovsky A.I., Murzina T.V. // J. Appl. Phys. 2012. V. 112. P. 013106.

[13] Ивченко Е.Л., Поддубный А.Н. // ФТТ. 2006. Т. 48. Вып. 3. C. 540.

[14] Горелик В.С., Филатов В.В. // Краткие сообщения по физике. 2010. № 2. С. 42.

[15] Горелик В.С., Филатов В.В. // Неорган. матер. 2012. Т. 48. № 4. C. 429.

[16] Горелик В.С., Лепнев Л.С., Литвинова А.О. // Неорган. матер. 2014. T. 50. С. 1086.

[17] Pavesi L. // Riv. Nuovo Cimento. 1997. V. 20. P. 1.

[18] Svyakhovskiy S.E., Maydykovsky A.I., Murzina T.V. // J. Appl. Phys. 2012. V. 112. P. 013106.

[19] Сивухин Д.В. // Опт. и спектр. 1957. Т. 3. Вып. 4. С. 308.

[20] Yariv A., Yeh P. Optical Waves in Crystals. Propagation and Control of Laser Radiation. N.Y.: Wiley, 1984. 589 p.

[21] Быков В.П. // ЖЭТФ. 1972. Т. 62. Вып. 2. С. 505.

[22] Asakawa K., Sugimoto Y., Watanabe Y., Ozaki N., Mizutani A., Takata Y., Kitagawa Y., Ishikawa H., Ikeda N., Awaz K., Wang X., Watanabe A., Nakamura S., Ohkouchi S., Inoue K., Kristensen M., Sigmund O., Bore P.I., Baets R. // New J. Phys. 2006. V. 8. P. 208.

[23] Lodahl P., van Driel A.F., Nikolaev1 I.S., Irman A., Overgaag K., Vanmaekelbergh D., Vos W.L. // Nature. 2004. V. 430. N 7000. P. 654.

[24] Ooi C.H.R., Au Yeung T.C., Kam C.H., Lim T.K. // Phys. Rev. B. 2000. V. 61. P. 5920.

[25] Wu C.-J., Chen M.-S., Yang T.J. // Physica C: Superconductivity. 2005. V. 432. P. 133. 